University of Wollongong

Research Online

Faculty of Engineering and Information

Faculty of Engineering and Information

Sciences - Papers: Part A

Sciences

$1-1-2016$

Integration of plug-in electric vehicles into microgrids as energy and reactive power providers in market environment

\author{
Abdorreza Rabiee \\ Shahrekord University, rabiee@iust.ac.ir \\ Hassan Feshki Farahani \\ Islamic Azad University \\ Mohammad Khalili \\ Shahid Beheshti University \\ Jamshid Aghaei \\ Shiraz University of Technology, jamshid@uow.edu.au \\ Kashem M. Muttaqi \\ University of Wollongong, kashem@uow.edu.au
}

Follow this and additional works at: https://ro.uow.edu.au/eispapers

Part of the Engineering Commons, and the Science and Technology Studies Commons

\footnotetext{
Research Online is the open access institutional repository for the University of Wollongong. For further information
} contact the UOW Library: research-pubs@uow.edu.au 


\title{
Integration of plug-in electric vehicles into microgrids as energy and reactive power providers in market environment
}

\author{
Abstract \\ The concept of electricity markets in the deregulated environment generally refers to energy market and \\ reactive power market is not paid attention as much as it deserves to. However, reactive power plays an \\ important role in distribution networks to improve network conditions such as voltage profile \\ improvement and loss reduction. Plug-in electric vehicles (PEVs) are mobile sources of active and \\ reactive power, capable of being participated in energy market, and also in reactive power market without \\ battery degradation. Active and reactive powers are coupled through the ac power flow equations and \\ branch loading limits, as well as PEVs and synchronous generators capability curves. This paper presents \\ a coupled energy and reactive power market in the presence of PEVs. The objective function is threefold, \\ namely offers cost (for energy market), total payment function (for reactive power market), and lost \\ opportunity cost, all to be minimized. The effectiveness of the proposed coupled energy and reactive \\ power market is studied based on a 134-node microgrid with and without PEV participation.
}

\section{Keywords}

into, vehicles, electric, energy, plug, integration, reactive, power, providers, microgrids, environment, market

Disciplines

Engineering | Science and Technology Studies

\section{Publication Details}

A. Rabiee, H. Feshki . Farahani, M. Khalili, J. Aghaei \& K. M. Muttaqi, "Integration of plug-in electric vehicles into microgrids as energy and reactive power providers in market environment," IEEE Transactions on Industrial Informatics, vol. 12, (4) pp. 1312-1320, 2016. 


\title{
Integration of Plug-in Electric Vehicles into Microgrids as Energy and Reactive Power Providers in Market Environment
}

\author{
A. Rabiee, H. Feshki. Farahani, M. Khalili, J. Aghaei \& K. M. Muttaqi
}

\begin{abstract}
The concept of electricity markets in the deregulated environment generally refers to energy market and reactive power market is not paid attention as much as it deserves to. However, reactive power plays an important role in distribution networks to improve network conditions such as voltage profile improvement and loss reduction. Plug in electric vehicles (PEVs) are mobile sources of active and reactive power, capable of being participated in energy market, and also in reactive power market without battery degradation. Active and reactive powers are coupled through the AC power flow equations and branch loading limits as well as PEVs and synchronous generators capability curves. This paper presents a coupled energy and reactive power market in the presence of PEVs. The objective function is three-fold namely, offers cost (for energy market), total payment function (TPF) (for reactive power market) and lost opportunity cost (LOC), all to be minimized. The effectiveness of the proposed coupled energy and reactive power market is studied based on a 134-node micro-grid with and without PEV participation.
\end{abstract}

Index Terms - Coupled energy and reactive power market, Expected payment function (EPF), plug in electric vehicles (PEVs), Lost opportunity cost (LOC), and total payment function (TPF).

\section{INTRODUCTION}

$\mathrm{R}$ eactive power has a major role in ensuring the reliability and security of power systems. It improves the voltage profile and increases the transferring power factor. There are many works in the area of reactive power compensation and production using SVCs and FACTS devices [1-2]. Reference [3] propose competitive reactive power market in single or multi-objective function optimization problem that the objectives are total payment function (TPF), overload index and voltage deviation index and voltage stability margin. The works in [4-6], incorporate PEVs in the reactive power market as a new reactive power source in the form of single objective and multi-objective functions. The objective function is to minimize TPF in [4], minimize TPF and grid losses in multi objective function in[5] and minimize the expected TPF in stochastic framework [6]. In[7], a coupled energy and active power market clearing considering power system security has been presented. In most of these papers, the synchronous generator has been used as the main source for reactive power.

The PEV technology has been deployed in an attempt to decrease greenhouse gases as well as air pollution in urban areas. PEVs have been considered as the subject of many studies and are expected to take the future of transportation [8]. PEVs have high capability in providing reactive power [9], incorporation in the ancillary service market [10], participating in demand response programs [11], even harmonic compensation as active filter [12], and it is integrated into microgrids as a micro-source and micro-storage systems [13] as well.

It is noted that the dollar paid for reactive power compensation is much lower than that for energy production. Therefore, clearing of the coupled energy and reactive power market is not in the interest of the bulk power system utilities. Besides that, in the coupled market, computing burden is greater respect to decoupled energy and reactive power markets. However in distribution systems and micro-grids, the required energy is likely to be provided by local sources and DGs, and thereby the concurrent optimization of active and reactive power supply could be the basis of many studies. Accordingly, in this paper, a coupled energy and reactive power market is proposed in the presence of PEVs in a microgrid. The main contribution of this paper is the development of a structural framework for the coupled energy and reactive power market in the context of microgirds incorporating PEVs where PEVs are allowed to participate actively in the reactive power market.

The remainder of this paper is as follow. In section II, the decoupled energy market, the decoupled reactive power market and the coupled energy and reactive power market with the incorporation of PEVs are discussed consecutively. Section III presents the case study and simulation results. Finally in section IV, we have conclusions.

\section{THE PROPOSED FRAMEWORK}

The formulation of coupled market in the presence of PEVs is presented in this section. At first, the decoupled energy and reactive power market are discussed in brief. Then the coupled energy and reactive power market is formulated.

\section{A. Decoupled energy market including PEVs}

Each PEV includes battery that can absorb/inject energy from/to grid as shown in Fig. 1. In fact, PEVs can participate in the energy market in the form of singular or integrated to inject/absorb energy from/to grid via V2G technology. In the energy market, the generators can only inject power to the grid while the PEVs can either inject or absorb energy from the grid. In other words, in comparison with generator for which power flow is unidirectional, the power transfer of PEVs is bidirectional. It is noted that the aggregators are third party entities that have the responsibility of participating in electricity markets on behalf of a large number of PEV owners with the aim of maximizing the profit through market mechanism while satisfying the owners' requirements. 

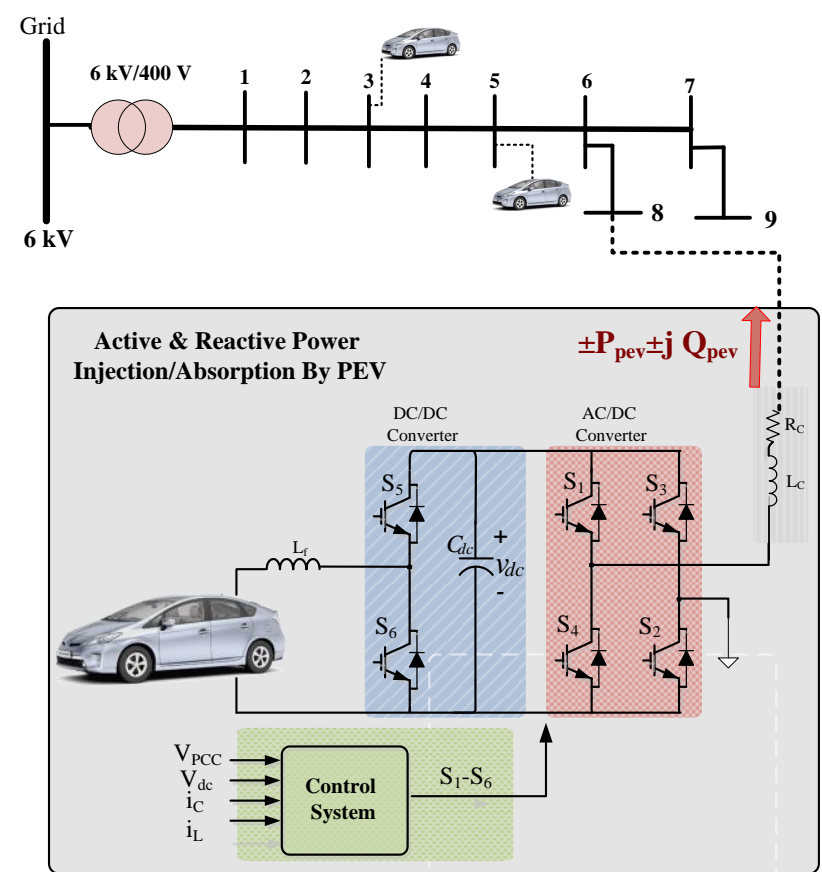

Fig. 1: Capability of PEV for injecting/absorbing active and reactive power into/from the grid via $\mathrm{V} 2 \mathrm{G}$ technology

Accordingly, the aggregators participate in the wholesale energy market. In that case, some aggregators participate in the power pool market as generators/loads to inject/absorb a large amount of electric power. So, the aggregators will be the same as other participants from the viewpoint of the independent system operator. But in this paper, a local market (retail market) has been considered such that the production and energy consumption is much lower than wholesale market. Also, this local market is considered as price-taker participant with respect to the upstream network market. In fact, the local market operator benefits the advantage of PEVs and uses them in order to reduce the costs of energy and reactive power. All in all, the proposed joint market framework can be adopted for the wholesale and retail markets. Accordingly, if it is considered for the wholesale market, then the aggregators can be modeled as a big PEV (as modeled in the following); in the case of retail market, also, it can be considered that small aggregators and individual PEVs can participate in the market.

Using power electronic converter in the PEVs structure, they can produce active, reactive and distorted power (to compensate of power system harmonics). Therefore, they can participate in the energy market, reactive power market and even harmonic power market, if exists. Therefore, in order to increase the incentive for PEV owners to participate in the energy market, the independent system operator (ISO) should use a suitable auction mechanism such that not only cover all costs of PEV owners, but also the PEV owners can maximize their profits.

The market can be cleared based on Pay-as-Bid or pay at market clearing price (MCP). In this paper the market is settled based on MCP mechanism to determine the corresponding payments for the selected generating units (PEV and generator) [7, 14-16]. The total payment in the energy market consists of two-part that are the payment of PEV owners and generator owners. Accordingly, the objective function of the energy market in the presence of PEVs is as follows:

Minimize $\left[\sum_{i=1}^{N_{G}}\left(\rho_{e}^{i} \times P_{G}^{i}\right)+\sum_{j=1}^{N_{P}}\left(\rho_{e}^{j} \times P_{P}^{j}\right)\right]$

where, $\rho_{e}^{i}$ and $\rho_{e}^{j}$ are bid price for energy for the $i^{\text {th }}$ generator unit and $j^{\text {th }}$ PEV unit, respectively; $P_{G}^{i}$ and $P_{P}^{j}$ are active power output of generators and PEVs in the energy market, respectively; $N_{G}$ and $N_{P}$ are number of generator and PEV units, respectively.

\section{B. Decoupled reactive power market in the presence of PEVS}

The PEV owners, should offer their price components based on the Expected Payment Function(EPF) [3]. This matter requires the capability curve of PEVs which is extracted from[4] and shown in Fig. 2.

According to Fig. 2, the apparent power output of PEV is limited by four curves. $A_{1}$ and $A_{2}$ are related to inverter maximum output power in kVA. Curves $B_{1}$ and $B_{2}$ are related to the maximum active power of PEV that is injected to the grid or absorbed from the grid.

Based on the capability curve of PEV shown in Fig. 2, the expected payment function (EPF) of PEV can be defined inspired by the EPF presented for synchronous generator in [3]. The EPF of PEV is shown in Fig. 3 and described in details in [4] which can be mathematically written as:

$$
\begin{gathered}
E P F_{j}=a_{0 j}+\int_{Q_{b^{\prime}}}^{Q_{M^{\prime}}}\left(m_{1 j} \cdot Q_{j}\right) \cdot d Q_{j}+\int_{Q_{b}}^{Q_{M}}\left(m_{2 j} \cdot Q_{j}\right) \cdot d Q_{j} \\
\quad+\int_{Q_{M}}^{Q_{N}}\left(m_{3 j} \cdot Q_{j}\right) \cdot d Q_{j}+\int_{Q_{M^{\prime}}}^{Q_{N^{\prime}}}\left(m_{4 j} \cdot Q_{j}\right) \cdot d Q_{j}
\end{gathered}
$$

where $a_{0 j}, m_{l j}, m_{2 j}, m_{3 j}$ and $m_{4 j}$ are the bid values of the $j^{\text {th }}$ PEV for the reactive power market. As shown in Fig. 3, the cost of loss and the opportunity cost, both are a quadratic function of $Q$. Also the EPF of generator is:

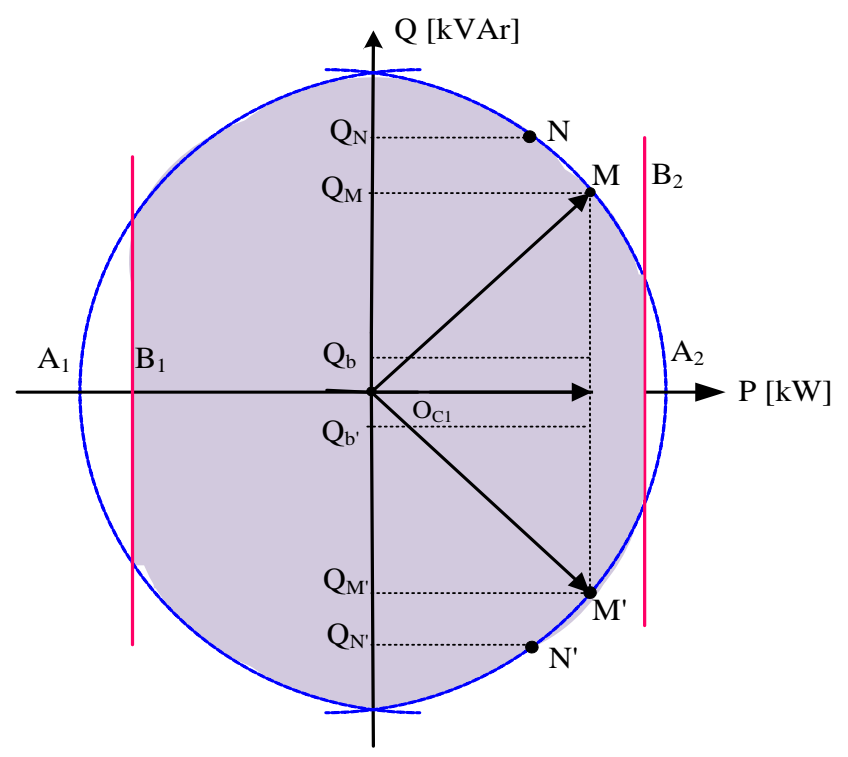

Fig.2. The capability curve of PEV 




Fig. 3: Reactive power offer structure of PEV.

$$
E P F_{G}^{i}=a_{0}^{i}+\int_{Q_{\text {Min }}}^{0} m_{1}^{i} d Q_{G}^{i}+\int_{Q_{\text {base }}}^{Q_{A}} m_{2}^{i} d Q_{G}^{i}+\int_{Q_{A}}^{Q_{B}} m_{3}^{i} Q_{G}^{i} d Q_{G}^{i}
$$

where $a_{0}^{i}$ is the availability price offer in dollars, $m_{1}^{i}$ is cost of loss price offer for operating in under excited mode $\left(Q_{\min }<Q \leq\right.$ 0 ) in $\$$ MVAr-h, $m_{2}^{i}$ is cost of loss price offer for operating in region $\left(Q_{\text {base }} \leq Q \leq Q_{A}\right)$ in $\$ / \mathrm{MVAr}-\mathrm{h}$ and $m_{3}^{i}$ is opportunity price offer for operating in region [3].

The reactive power is settled based on the minimization of total payment function (TPF) paid to the participants of reactive power market. In other words, the objective function of the cost minimization problem is the EPF of PEVs plus the EPF of synchronous generators. Therefore, the total payment will depend on the market price of the five components of the bid prices offered by the PEVs and four components of the bid prices offered by synchronous generators. The total payment function (TPF) is formulated as follows:

$T P F=T P F_{i}+T P F_{j}$

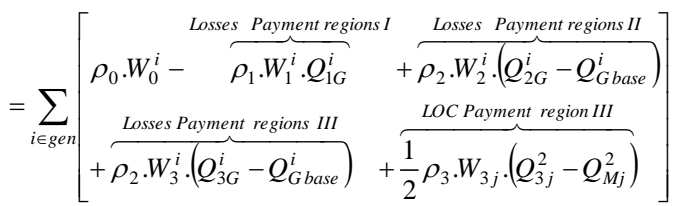

$$
\begin{aligned}
& +\sum_{j \in P H E V}\left[\begin{array}{c}
\rho_{0} \cdot W_{0 j} \\
+\overbrace{\frac{1}{2} \rho_{1} \cdot W_{1 j} \cdot\left(Q_{1 j}^{2}-Q_{b^{\prime} j}^{2}\right)+\frac{1}{2} \rho_{1} \cdot W_{4 j} \cdot\left(Q_{4 j}^{2}-Q_{b^{\prime} j}^{2}\right)}^{\text {Losses Payment regionsI,IV }}+\overbrace{\frac{1}{2} \rho_{4} \cdot W_{4 j} \cdot\left(Q_{4 j}^{2}-Q_{M^{\prime} j}^{2}\right)}^{\text {LOC Payment region IV }} \overbrace{\frac{1}{2} \rho_{3} \cdot W_{3 j} \cdot\left(Q_{3 j}^{2}-Q_{M j}^{2}\right)}^{\text {LOC Payment region III }} \\
+\overbrace{\frac{1}{2} \rho_{2} \cdot W_{2 j} \cdot\left(Q_{2 j}^{2}-Q_{b j}^{2}\right)+\frac{1}{2} \rho_{2} \cdot W_{3 j} \cdot\left(Q_{3 j}^{2}-Q_{b^{\prime} j}^{2}\right)}^{\text {Losses Payment regions II,III }}
\end{array}\right]
\end{aligned}
$$

where $\rho_{0}, \rho_{1}, \rho_{2}, \rho_{3}$, and $\rho_{4}$ are the market clearing prices (MCPs) of offer prices of market participants for $a_{0}, m_{1}, m_{2}$, $m_{3}$ and $m_{4}$, respectively which are accepted in the reactive power market. The discussion for $T P F_{i}$ is the same as what found in[3, 17]. However, $T P F_{j}$ deserves more explanation. According to (4), the PEV owner is paid for losses payment as it enter region I, IV for reactive power absorption, and region II, III for reactive power production. Despite the synchronous generator (which is a linear function), the losses payment of $\mathrm{PEV}$ is quadratic function of PEV reactive power output. The LOC payment of PEV is similar to that of synchronous generator which is a quadratic function of its reactive power output $[5,7]$. The objective function (4) is minimized subjected to the following equality and inequality constraints.
- Load flow constraints:

$P_{k}^{\text {gen }}-P_{k}^{d}+P_{k}^{\text {PHEV }}=\sum_{j} V_{k} V_{l} Y_{k l} \cos \left(\delta_{k}-\delta_{l}-\theta_{k l}\right)$
$Q_{k}^{g e n}-Q_{k}^{d}+Q_{k}^{\text {PHEV }}=\sum_{j} V_{k} V_{l} Y_{k l} \sin \left(\delta_{k}-\delta_{l}-\theta_{k l}\right)$

where, $k$ and $l$ are bus indices.

- The operation constraints of generators [18]:

$W_{0, i}, W_{1, i}, W_{2, i}, W_{3, i} \in\{0,1\} ; i \in$ the generator index

$Q_{i}=Q_{1 i}+Q_{2 i}+Q_{3 i}$

$W_{1, i} \cdot Q_{\text {min }, i} \leq Q_{1 i} \leq 0$

$W_{2, i} \cdot Q_{\text {base }, i} \leq Q_{2 i} \leq W_{2, i} \cdot Q_{A, i}$

$W_{3, i} \cdot Q_{A, i} \leq Q_{3 i} \leq W_{3, i} \cdot Q_{B, i}$

$W_{1, i}+W_{2, i}+W_{3, i} \leq W_{0, i}$

It is noted that, $Q_{A}$ is the point at which synchronous generators enter to LOC region to generate reactive power $Q_{B}$.

- The operation constraints of PEV[5, 7]:

$W_{0 j}, W_{1 j}, W_{2 j}, W_{3 j}, W_{4 j} \in\{0,1\} ; j \in$ PHEVs index

$Q_{j}=Q_{1 j}+Q_{2 j}+Q_{3 j}+Q_{4 j}$

$W_{1 j} \cdot Q_{b j} \leq Q_{1 j} \leq W_{1 j} \cdot Q_{M j}$

$W_{2 j} \cdot Q_{M j} \leq Q_{2 j} \leq W_{2 j} \cdot Q_{N j}$

$W_{3 j} \cdot Q_{b^{\prime}} \leq Q_{3 j} \leq W_{3 j} \cdot Q_{M^{\prime} j}$

$W_{4 j} \cdot Q_{M^{\prime}} \leq Q_{4 j} \leq W_{4 j} \cdot Q_{N^{\prime} j}$

$W_{1, j}+W_{2, j}+W_{3, j}+W_{4, j} \leq W_{0, j}$

Where, $Q_{1 j}, Q_{2 j}, Q_{3 j}$, and $Q_{4 j}$ based on Fig. 3, represent the regions $\left(Q_{b^{\prime}}\right.$ to $\left.Q_{M^{\prime}}\right),\left(Q_{b}\right.$ to $\left.Q_{M}\right),\left(Q_{M}\right.$ to $\left.Q_{N}\right)$, and $\left(Q_{M^{\prime}}\right.$ to $\left.Q_{N^{\prime}}\right)$, respectively. $W_{1 j}, W_{2 j}, W_{3 j}$ and $W_{4 j}$ are binary variables, showing the compensation region of the PEV. If the $j^{\text {th }} \mathrm{PEV}$ is participated in the reactive power market and operated in region $\left(Q_{b^{\prime}}\right.$ to $\left.Q_{b}\right)$, then $W_{0 j}=1$ and $W_{1 j}=W_{2 j}=W_{3 j}=W_{4 j}=0$. If the accepted unit is operated in region I $\left(Q_{b^{\prime}}\right.$ to $\left.Q_{M^{\prime}}\right)$ then $W_{0 j}=$ $W_{1 j}=1$ and $\mathrm{W}_{2 \mathrm{j}}=W_{3 j}=W_{4 j}=0$. If the unit is operated in region II $\left(Q_{b}\right.$ to $\left.Q_{M}\right)$ then $W_{0 j}=W_{2 j}=1$ and $W_{1 j}=W_{3 j}=W_{4 j}=0$. If the unit is operated in region III $\left(Q_{M}\right.$ to $\left.Q_{N}\right)$ then $W_{0 j}=W_{3 j}=$ 1 and $W_{1 j}=W_{2 j}=W_{4 j}=0$, and if the unit is operated in region IV $\left(Q_{M^{\prime}}\right.$ to $\left.Q_{N^{\prime}}\right)$ then $W_{0 j}=W_{4 j}=1$ and $W_{1 j}=W_{2 j}=W_{3 j}=0$. When the $j^{\text {th }} \mathrm{PEV}$ is not selected or is selected and operated in one of the regions I, II, III, IV then the constraint (19) will be satisfied in the equality form (i.e. $0=0$ or $1=1$, respectively). However, when the $j^{\text {th }} \mathrm{PEV}$ is selected for reactive power reserve of network, then constraint (19) will be satisfied in the inequality form (i.e. $0<1$ ).

- Constraints related to determination of MCPs of price components in reactive power market:

$W_{0, i} a_{0, i} \leq \rho_{0}$

$W_{1, i} m_{1, i} \leq \rho 1$

$\left(W_{2, i}+W_{3, i}\right) m_{2, i} \leq \rho_{2}$

$W_{3, i} m_{3, i} \leq \rho_{3}$

$W_{0 j} a_{0 j} \leq \rho_{0}$

$\left(W_{1 j}+W_{4 j}\right) m_{1 j} \leq \rho_{1}$ 
$\left(W_{2 j}+W_{3 j}\right) m_{2 j} \leq \rho_{2}$

$W_{3 j} m_{3 j} \leq \rho_{3}$

$W_{4 j} m_{4 j} \leq \rho_{4}$

- PEV capability curve constraints:

$\left(P_{j}+P_{j, \text { loss }}\right)^{2}+Q_{j}^{2} \leq S_{j, n}{ }^{2}$

For discharging mode (curve $\mathrm{A}_{2}$ )

$\left(P_{j}-P_{j, l o s s}\right)^{2}+Q_{j}^{2} \leq S_{j, n}{ }^{2}$

For charging mode (curve $\mathrm{A}_{1}$ )

$P_{j, a-} \leq P_{j} \leq P_{j, a+}$

Maximum PEV output power (Curves B1 and B2):

$S_{j, n}$ is the nominal apparent output power of $j^{\text {th }} \mathrm{PEV}$ and $P_{j, a+}$ and $P_{j, a-}$ are the maximum discharging and charging active power of PEV, respectively which are determined by PEV owners.

- Generators capability curve constraints:

$Q_{g}^{i} \leq \sqrt{\left(V_{t}^{i} \cdot I_{a}^{i}\right)^{2}-\left(P_{g}^{i}\right)^{2}}$

Capability curve limit (armature current limit):

$Q_{g}^{i} \leq \sqrt{\left(\frac{V_{t}^{i} \cdot E_{a f}^{i}}{X_{s}^{i}}\right)^{2}-\left(P_{g}^{i}\right)^{2}}-\frac{\left(V_{t}^{i}\right)^{2}}{X_{s}^{i}}$

Capability curve limit (Field current limit):

$V_{t}$ is generator terminal voltage, $E_{a f}$ is the excitation voltage, $I_{a}$ is the armature current and $X_{s}$ is the synchronous reactance of synchronous generator. More details of synchronous generator capability curve can be found in [7, 17-19].

\section{Coupled energy and reactive power markets}

In the electricity market, any decreasing of active power due to increasing of reactive power must be remunerated. In other words, the LOC payment must be considered in the payment function. From (4), it can be seen that the LOC payment is a quadratic function of produced reactive power for both PEV and synchronous generator. In couple and decouple market, PEV and generator will be paid for the LOC for reduction of active power generation but in a different formulation. In the coupled market, the LOC is formulated in a different way compared with that of the decoupled reactive power market. So, in this subsection at first, the formulation of LOC consideration in the coupled market is explained and then the proposed coupled framework is introduced and discussed.

\section{1) LOC consideration in decoupled and coupled markets}

The LOC of a PEV and generator in the coupled market, are calculated based on the MCP of the energy-only market as well as their bid prices in the market and it includes two parts as follows:
$L O C=\sum_{i=1}^{N_{G}} L O C_{G}^{i}+\sum_{j=1}^{N_{G}} L O C_{P}^{j}$

$\operatorname{LOC}_{G}^{i}=\max \left\{0, \operatorname{LOP} P_{G}^{i}\left(P_{G 0}^{i}-P_{G}^{i}\right)\right\}$

$\operatorname{LOC}_{P}^{j}=\max \left\{0, \operatorname{LOP}_{P}^{j}\left(P_{P 0}^{j}-P_{P}^{j}\right)\right\}$

where, $\operatorname{LOC}_{G}^{i}$ and $L O C_{P}^{j}$ are related to generator and PEV, respectively. $P_{G 0}^{i}$ and $P_{P 0}^{j}$ represent the active power output of the $i^{\text {th }}$ generator unit and $j^{\text {th }}$ PEV unit in the energy-only market respectively, and $P_{G}^{i}$ and $P_{P}^{j}$ represent the active power output of the $i^{\text {th }}$ generator unit and $j^{\text {th }} \mathrm{PEV}$ unit in coupled market, respectively. The variables $L O P_{G}^{i}$ and $L O P_{P}^{j}$ are defined as follow [7]:

$L O P_{G}^{i}=\left\{\begin{array}{cc}\rho_{e, M C P}-\rho_{e, g e n}^{i} & \rho_{e, M C P}>\rho_{e, g e n}^{i} \\ 0 & \rho_{e, M C P} \leq \rho_{e, g e n}^{i}\end{array}\right.$

$L O P_{P}^{j}=\left\{\begin{array}{lc}\rho_{e, M C P}-\rho_{e, p e v}^{j} & \rho_{e, M C P}>\rho_{e, p e v}^{j} \\ 0 & \rho_{e, M C P} \leq \rho_{e, p e v}^{j}\end{array}\right.$

where, $\rho_{e, g e n}^{i}$ and $\rho_{e, p e v}^{j}$ indicate the bid price of the $i^{\text {th }}$ generator unit and $j^{\text {th }} \mathrm{PEV}$ unit in the energy market, respectively and $\rho_{e, M C P}$ represents the market clearing price of the energy-only market. From (35) and (36) it can be seen that only the PEV and generator units accepted in the energy-only market might be paid for their LOC.

\section{2) TPF consideration in decoupled and coupled markets}

In the proposed coupled market, the quadratic term of the TPF related to the LOC payment is substituted by the new formulation described in (34) to (36). Therefore, the TPF for reactive power compensation in the coupled market only includes availability and loss payments as follows [7]:

$$
\begin{array}{r}
T P F=T P F_{\text {gen }}+T P F_{\text {phev }}=\sum_{i \in g e n}\left[\begin{array}{l}
\rho_{0} \cdot W_{0, i}-\rho_{1} \cdot W_{1, i} \cdot Q_{1 G}^{i} \\
+\rho_{2} \cdot W_{2}^{i, C} \cdot\left(Q_{2 G}^{i}-Q_{G \text { base }}^{i}\right)
\end{array}\right] \\
+\sum_{j \in P H E V}\left[\begin{array}{l}
\rho_{0} \cdot W_{0 j}+\frac{1}{2} \rho_{1} \cdot W_{1 j}^{C} \cdot\left(Q_{1 j}^{2}-Q_{b^{\prime} j}^{2}\right) \\
+\frac{1}{2} \rho_{2} \cdot W_{2 j}^{C} \cdot\left(Q_{2 j}^{2}-Q_{b j}^{2}\right)
\end{array}\right]
\end{array}
$$

The TPF includes two terms: first term is related to generators payment and the second one is to PEVs. The two regions $\left(Q_{\text {base }}-Q_{A}\right)$ and $\left(Q_{A}-Q_{B}\right)$ are merged in first part of (37) compared with (4), since both regions have the same operation payment so, $W_{2 j}^{C}$ refers to the two merged regions in the coupled market. Similar to that for generator, in PEV, the regions $\left(Q_{b}-Q_{M}\right)$ and $\left(Q_{M}-Q_{N}\right)$ and the regions $\left(Q_{b}-Q_{M}\right)$ and $\left(Q_{M}-Q_{N}\right)$ are merged in the second part of (4) as written in (37). $W_{1 j}^{C}$ and $W_{2 j}^{C}$ are binary variable indicating the operation in regions $\left(Q_{b}-Q_{N}\right)$ and $\left(Q_{b}-Q_{N}\right)$, respectively. 


\section{3) Objective function in the coupled markets}

The objective function of the coupled energy and reactive power market is composed of the offer cost of generating units and PEVs for their active power production, the TPF of units for their reactive power compensation and the LOC payment of the units as:

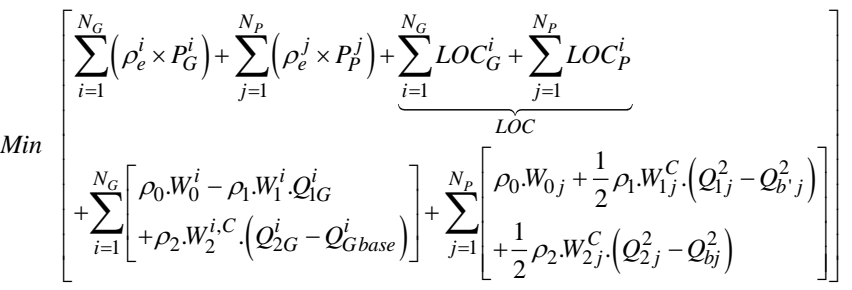

(38)

where, $N_{G}$ and $N_{P}$ are the number of synchronous generators and PEVs, respectively. In (38), the first and second term refer to offer cost of generating units and PEVs in energy market. Also, the third and fourth terms are the LOC of generating units and PEVs as well. TPF of generating units and PEVs for participating in reactive market have been addressed in fifth and sixth terms. As it can be seen, the objective function is in the form of MINLP due to presence of binary variables $W_{1 j}$, $W_{2 j}, W_{3 j}$ and $W_{4 j}$ as well as quadratic formulation in the last term of (38).The objective function (38) is minimized subjected to the following equality and inequality constraints:

- Load flow constraints:

Constraints (5) and (6) are used to validate for this objective function.

- The operation constraints of generators:

$W_{0, i}, W_{1, i}, W_{2}^{i, C} \in\{0,1\} ; i \in$ the generator index

$Q_{i}=Q_{1 i}+Q_{2 i}^{C}$

$W_{1, i} \cdot Q_{\text {min, } i} \leq Q_{1 i} \leq 0$

$W_{2}^{i, C} \cdot Q_{\text {base }, i} \leq Q_{2 i}^{C} \leq W_{2}^{i, C} \cdot Q_{B, i}$

$W_{1, i}+W_{2}^{i, C} \leq W_{0, i}$

- The operation constraints of PEV:

$W_{0 j}, W_{1}^{j, C}, W_{2}^{j, C} \in\{0,1\} ; j \in P H E V$ s index

$Q_{j}=Q_{1 j}+Q_{2 j}$

$W_{1}^{j, C} \cdot Q_{b^{\prime} j} \leq Q_{1 j} \leq W_{1}^{j, C} \cdot Q_{N^{\prime} j}$

$W_{2}^{j, C} \cdot Q_{b} \leq Q_{2 j} \leq W_{2}^{j, C} \cdot Q_{N j}$

$W_{1}^{j, C}+W_{2}^{j, C} \leq W_{0, j}$

where, $Q_{l j}$ and $Q_{2 j}$ represent the regions $\left(Q_{b^{\prime}}\right.$ to $\left.Q_{N^{\prime}}\right)$ and ( $Q_{b}$ to $\left.Q_{N}\right)$ respectively. $W_{1}^{j, C}$ and $W_{2}^{j, C}$ are binary variable, showing the compensation region of the PEV.

- Constraints related to determination of MCPs of price components in reactive power market:

$W_{0, i} a_{0, i} \leq \rho_{0}$

$W_{1, i} m_{1, i} \leq \rho 1$

$W_{2}^{i, C} m_{2, i} \leq \rho_{2}$

$W_{0, j} a_{0, j} \leq \rho_{0}$
$W_{1}^{j, C} m_{1, j} \leq \rho_{1}$

$W_{2}^{j, C} m_{2, j} \leq \rho_{2}$

- PEV capability curve constraints

Constraints (29) to (31) are validate for this objective function.

\section{- Generators capability curve constraints}

Constraints (32) and (33) are valid for this objective function. The MINLP optimization problem of (38) to (54) is modeled in GAMS software using DICOPT solver [20]. The DICOPT solver is based on the extensions of the outer approximation algorithm for the equality relaxation strategy. It iteratively invokes the MINOS5 and XA10.0 solvers for nonlinear (NLP) and mixed-integer-programming (MIP) solutions, respectively [20]. The GAMS/DICOPT algorithm has built-in provisions to handle non-convexities, and hence, we can, with a fair degree of confidence, rely on the GAMS/DICOPT optimal solutions to be globally optimal [20]. It should be mentioned however that, there are some works ongoing in the area of global optimization methods [21-22], and improved techniques (or solvers with higher confidence levels) should appear in the literature in the coming years [22].

\section{CASE STUDY}

To transfer power between grid and PEV, there must be a suitable communication infrastructure and metering devices in the power system, which can be found in a smart grid. For the analytical studies, a realistic low voltage residential distribution network is used. This network is related to a suburban area of Dublin, Ireland. Fig. 4 shows the one-line diagram of this feeder. This feeder, supplies 134 single-phase households and $17 \mathrm{PEVs}$ which household loads are served at a lag power factor of 0.9 and PEV batteries are modeled as constant loads with unity power factor. The non-unity power factor of loads is assumed in order to reactive power studies purposes. The total number of PEVs connected to network is 17. More details about this network are available in [23].

Also, in this study, the maximum transferable reactive power between grid and PEV is considered about $5 \mathrm{kVar}$ (level-3 charging, the maximum output power is equal up to $16.8 \mathrm{~kW}(240 \mathrm{~V}, 70 \mathrm{~A})$ [9, 24-25]).To study our proposed coupled market framework, besides clearing of the coupled active and reactive power market, the energy and reactive power market are cleared in the form of decoupled. In other words, three markets are cleared and all of them are cleared for peak loading conditions of network and with and without participation of PEVs. Furthermore, it is supposed that only synchronous generator and PEVs are considered as the participant of the markets.

Also, in this paper, the consumers are considered as price taker loads and inelastic to avoid the unnecessary intricacies. So, the consumers load is considered as non-deferrable and non-interruptible demands that always have been served.

It is noted that, in the energy market, generator and PEVs submits their offer prices and the outputs of synchronous generator and PEVs in the energy market are the boundary of participant wherein they entered to LOC region and should be paid for the LOC payment by the ISO if they are accepted in the reactive power market and operated in the LOC region. In 


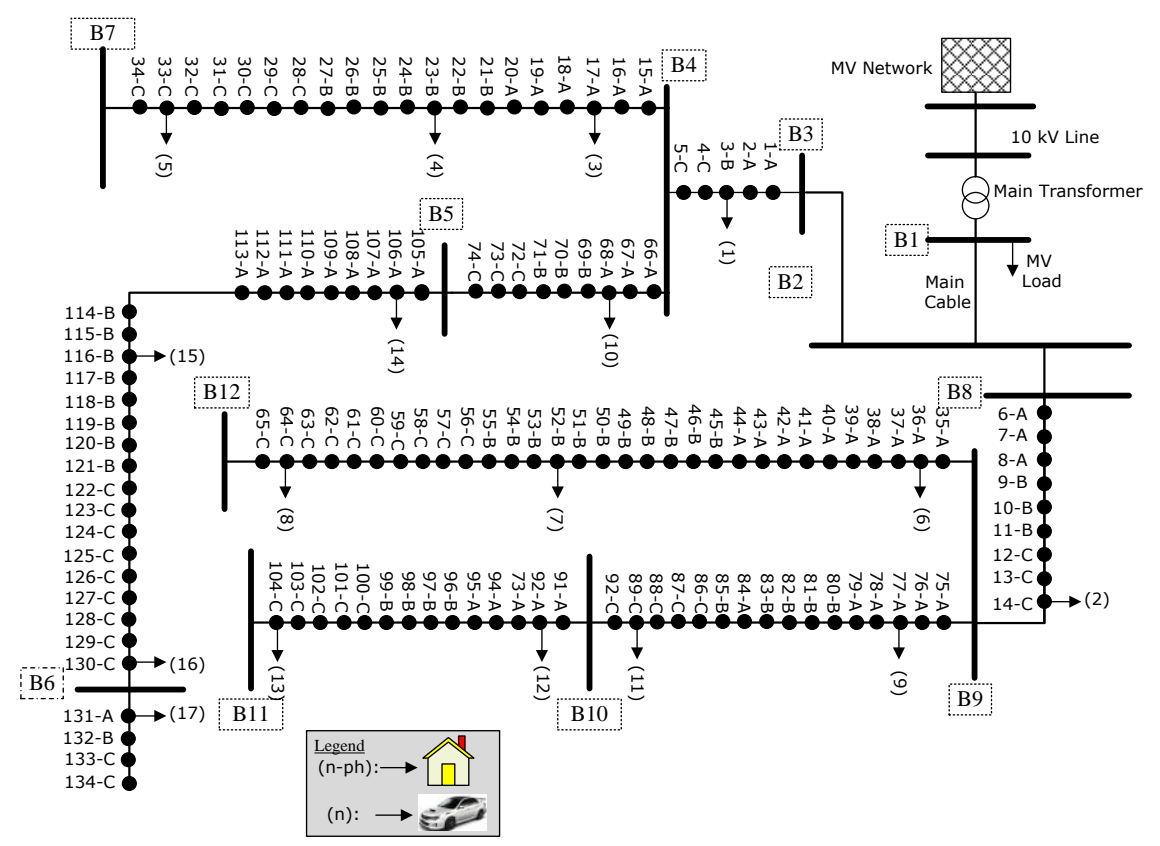

Fig. 4. The modified version of 134-node LV network

other words, the $\left(P_{A}, Q_{A}\right)$ of synchronous generator [3, 7] and $\left(P_{M}, Q_{M}\right)$ of PEVs [4-6] are determined based on their output in the energy market cleared previously.

In our study, generator as a reactive power provider submits its four-component price offers, i.e. $a_{0}, m_{1}, m_{2}$, and $m_{3}$ while, the owners of PEVs, similar to the works in[4-6], offer their five-component price as $a_{0}, m_{1}, m_{2}, m_{3}$, and $m_{4}$ in order to participate in the reactive power market. The price offers of energy and reactive power market participants are given in Table 1 . The optimization problem of reactive power market clearing is in the form of mixed integer non-linear programming (MINLP) that is modeled in GAMS software using DICOPT solver [20].

The results of energy market clearing with PEVs (Case 1) and without incorporation of PEVs (Case 2) are listed in Table 2.

In the case of participation of PEVs, the total payment to participants (PEV + Generator) is 24.39 \$ that includes $3.15 \$$ for PEVs and 21.24 \$ for generator.

The outputs of PEV \#6, \#11, \#14 and \#17 in the energy market are zero. In other words, their offers are not accepted in the market due to their high offer prices. The offer price of generator is lower than that of the PEV; therefore, the generator increases its output power to meet the system demand. In the competitive market, each player offers the lower price for its production, has the greater chance of being selected in the market. The results of decoupled reactive power market clearing are shown in Table 3. The system reactive power demand is $216.78 \mathrm{kVAr}$ of which $56.51 \mathrm{kVar}$ is supplied by PEVs and $160.27 \mathrm{kVar}$ by generator. In this case, some of the PEVs enter to the LOC region and ISO preferred to purchase the reactive power from PEV, which is cheaper than generator due to their offer prices. Because of low offer price of PEV \#2, \#4, \#5, \#8, \#12 and \#16along with generator for minimizing total payment, enter to LOC region and ISO provides the required reactive power from them.
Table 1: Active and reactive power offer prices of participant PEVs and Synchronous Generator (SG)

\begin{tabular}{|c|c|c|c|c|c|c|c|}
\hline \multirow{2}{*}{$\begin{array}{l}\text { Node } \\
\text { No. }\end{array}$} & \multirow{2}{*}{$\begin{array}{l}\text { PEV } \\
\text { No. }\end{array}$} & \multirow{2}{*}{$\begin{array}{c}\text { Offer price } \\
\text { for active } \\
\text { power } \\
(\$ / \mathrm{kWh})\end{array}$} & \multicolumn{5}{|c|}{$\begin{array}{c}\text { Components of offer prices for reactive } \\
\text { power }\end{array}$} \\
\hline & & & $m_{4}$ & $m_{l}$ & $a_{0}$ & $m_{2}$ & $m_{3}$ \\
\hline 3 & 1 & 4.12 & 0.7 & 0.73 & 0.09 & 0.73 & 0.7 \\
\hline 14 & 2 & 5.28 & 0.79 & 0.6 & 0.1 & 0.6 & 0.79 \\
\hline 17 & 3 & 5.59 & 0.83 & 0.57 & 0.09 & 0.57 & 0.83 \\
\hline 23 & 4 & 4.96 & 0.6 & 0.48 & 0.1 & 0.48 & 0.6 \\
\hline 33 & 5 & 3.68 & 0.83 & 0.52 & 0.07 & 0.52 & 0.83 \\
\hline 36 & 6 & 6.96 & 0.61 & 0.54 & 0.09 & 0.54 & 0.61 \\
\hline 52 & 7 & 4.23 & 0.7 & 0.36 & 0.1 & 0.36 & 0.7 \\
\hline 64 & 8 & 3.82 & 0.7 & 0.46 & 0.08 & 0.46 & 0.7 \\
\hline 77 & 9 & 5.41 & 0.82 & 0.49 & 0.1 & 0.49 & 0.82 \\
\hline 68 & 10 & 4.37 & 0.79 & 0.56 & 0.08 & 0.56 & 0.79 \\
\hline 89 & 11 & 6.49 & 0.77 & 0.46 & 0.07 & 0.46 & 0.77 \\
\hline 92 & 12 & 4.63 & 0.72 & 0.38 & 0.1 & 0.38 & 0.72 \\
\hline 104 & 13 & 5.71 & 0.67 & 0.54 & 0.08 & 0.54 & 0.67 \\
\hline 106 & 14 & 6.19 & 0.69 & 0.57 & 0.08 & 0.57 & 0.69 \\
\hline 116 & 15 & 4.22 & 0.68 & 0.56 & 0.11 & 0.56 & 0.68 \\
\hline 130 & 16 & 5.3 & 0.77 & 0.48 & 0.08 & 0.48 & 0.77 \\
\hline 131 & 17 & 6.86 & 0.6 & 0.47 & 0.1 & 0.47 & 0.6 \\
\hline Grid Gen. & - & 5.75 & 0.7 & 0.82 & 0.1 & 0.82 & 0.7 \\
\hline
\end{tabular}

The total payment in the reactive power market is $5.96 \$$ of which 491.42 cents of dollar is paid for generator and 104.54cents of dollar for PEVs. The details of this payment are listed in four last column of Table 3. The LOC cost only paid to participants that enter to LOC region. To evaluate the presence of PEVs in the reactive power market, none of them incorporated in the market and the required reactive power is provided by the generator. Therefore, due to increasing the output reactive power of generator, it enters to LOC region and causes to increase the total payment of generator. The total payment of generator is $15.03 \$$ which is composed of 
Table 2: Optimal solution of energy-only market for peak loading condition

\begin{tabular}{cccc}
\multicolumn{4}{c}{ (decoupled market) } \\
\hline Node No. & PEV No. & P $_{\text {generated }}(\mathrm{kWh})$ & Energy Cost $(\$)$ \\
\hline 3 & 1 & 3.38 & 19.43 \\
14 & 2 & 4.82 & 27.72 \\
17 & 3 & 4.57 & 26.28 \\
23 & 4 & 4.53 & 26.05 \\
33 & 5 & 4.91 & 28.23 \\
36 & 6 & 0 & 0 \\
52 & 7 & 3.54 & 20.36 \\
64 & 8 & 4.97 & 28.58 \\
77 & 9 & 4.05 & 23.29 \\
68 & 10 & 4.07 & 23.4 \\
89 & 11 & 0 & 0 \\
92 & 12 & 4.64 & 26.68 \\
104 & 13 & 4 & 23 \\
106 & 14 & 0 & 0 \\
116 & 15 & 3.04 & 17.48 \\
130 & 16 & 4.17 & 23.98 \\
131 & 17 & 0 & 0 \\
Grid Gen. & - & 396.5 & $\mathbf{2 4 3 9}$ \\
\hline \multicolumn{5}{c}{ Total } & & $\mathbf{4 5 1 . 1 9}$ & \\
\hline
\end{tabular}

three components: availability payment that is low, losses payment that is 234.2 cents of dollar and LOC payment that is much greater than the other payments. Accordingly, the participation of PEV in the reactive power market causes the generator not to enter in the LOC region and thereby the payment in the reactive power market decreases remarkably.

Finally, the coupled active and reactive market is cleared in the presence of PEVs and the results are reported in Table. 4. In the coupled market, each participant is supposed to generate its active and reactive power in the region determined by its capability curve. In the coupled energy and reactive power market, a PEV could generate active power or reactive power simultaneously, for which the percentage of each power production is determined from its offer price for output active and reactive power and market clearing price. Therefore, each PEV would share its capacity to active and reactive power generation. The total payment for PEVs and generator is 2726.64 cents of dollars and composed of three components: 2492.77 cents of dollar for offer cost due to active power generation, 198.48 cents of dollar (TPF) for reactive power generation, and 35.39 cents of dollar for loss of opportunity (LOC). Incorporation of PEVs causes the generators not to enter to the LOC region.

In the case of not participating PEVs in the coupled energy and reactive power market, the ISO must pay more payment for generator owing to increasing of its output power and entering to LOC region. In this case, the total payment will increase from 2726.64 cents of dollar to 2966.04 cents of dollar, of which2690.94 cents of dollar for cost of active power generation, 238.69 cents of dollar for reactive power production (TPF) and 36.41 cents of dollar for LOC payment. All of these three terms are increased as compared to the case of PEV participation in the market.

Table 3: Optimal solution of reactive market for peak loading condition (decoupled reactive power market)

\begin{tabular}{|c|c|c|c|c|c|c|c|}
\hline \multirow{2}{*}{$\begin{array}{l}\text { Case } \\
\text { No. }\end{array}$} & \multirow{2}{*}{$\begin{array}{l}\text { Node } \\
\text { No. }\end{array}$} & \multirow{2}{*}{$\begin{array}{c}\text { PE } \\
\text { V } \\
\text { No. }\end{array}$} & \multirow{2}{*}{$\begin{array}{l}\mathrm{Q}_{\text {generated }} \\
\text { (kVAr) }\end{array}$} & \multicolumn{4}{|c|}{ Cost of (Cents in \$) } \\
\hline & & & & $\begin{array}{c}\text { Availabilit } \\
\text { y }\end{array}$ & Loss & LOC & TPF \\
\hline \multirow{20}{*}{$\begin{array}{l}\text { Case 1: } \\
\text { With } \\
\text { PEVs }\end{array}$} & 3 & 1 & 4.45 & 0.16 & 2.16 & 0 & 2.32 \\
\hline & 14 & 2 & 4.7 & 0.16 & 2.29 & 1.68 & 4.13 \\
\hline & 17 & 3 & 2.1 & 0.16 & 0 & 0 & 0.16 \\
\hline & 23 & 4 & 4.36 & 0.16 & 6.36 & 4.64 & 11.17 \\
\hline & 33 & 5 & 0.36 & 0.16 & 8.73 & 9.6 & 18.49 \\
\hline & 36 & 6 & 3.95 & 0.16 & 1.18 & 0 & 1.33 \\
\hline & 52 & 7 & 3.43 & 0.16 & 2.98 & 0 & 3.14 \\
\hline & 64 & 8 & 4.11 & 0.16 & 3.33 & 3.79 & 7.28 \\
\hline & 77 & 9 & 2.99 & 0.16 & 1.73 & 0 & 1.89 \\
\hline & 68 & 10 & 1.93 & 0.16 & 2.36 & 0 & 2.52 \\
\hline & 89 & 11 & 2.26 & 0.16 & 0 & 0 & 0.16 \\
\hline & 92 & 12 & 4.45 & 0.16 & 10.73 & 10.27 & 21.16 \\
\hline & 104 & 13 & 2.91 & 0.16 & 0.66 & 0 & 0.82 \\
\hline & 106 & 14 & 4.54 & 0.16 & 5.08 & 0 & 5.24 \\
\hline & 116 & 15 & 3.44 & 0.16 & 0 & 0 & 0.16 \\
\hline & 130 & 16 & 3.7 & 0.16 & 13.35 & 10.69 & 24.2 \\
\hline & 131 & 17 & 2.83 & 0.16 & 0.21 & 0 & 0.37 \\
\hline & $\begin{array}{l}\text { Grid } \\
\text { Gen. }\end{array}$ & - & 160.27 & 0.16 & $\begin{array}{c}119.0 \\
1\end{array}$ & 372.25 & 491.42 \\
\hline & \multirow{2}{*}{\multicolumn{2}{|c|}{$\Sigma$}} & 216.7 & & 180.1 & & \\
\hline & & & 8 & 2.88 & 6 & 412.92 & $\mathbf{5 9 5 . 9 6}$ \\
\hline \multirow{4}{*}{$\begin{array}{c}\text { Case 2: } \\
\text { Without } \\
\text { PEVs }\end{array}$} & \multirow{2}{*}{\multicolumn{2}{|c|}{ Grid Gen. }} & & & & 1269.0 & 1503.3 \\
\hline & & & 218.41 & 0.16 & 234.2 & 4 & 9 \\
\hline & \multirow{2}{*}{\multicolumn{2}{|c|}{$\sum$}} & 218.4 & & & 1269.0 & 1503.3 \\
\hline & & & 1 & 0.16 & 234.2 & 4 & 9 \\
\hline
\end{tabular}

The results presented in Table 4 also show the payment in decoupled active and reactive power markets. The payment in the coupled market is 279.54 cents of dollar (3006.182726.64) lower than those of decoupled energy and reactive power market. In other words, the proposed coupled market framework in the presence of PEVs can reach to a better optimum solution than the commonly used decoupled active and reactive power markets.

\section{CONCLUSION}

In this paper, a new framework is proposed for coupled energy and reactive power market in the presence of PEVs. The objective includes cost of energy, TPF of each unit (PEVs and generators) for their reactive power production and LOC of units due to the decrease in their active power generation to provide more reactive power. The new formulation of LOC in the coupled market is based on the MCP of the energy-only market. Using this framework, the ISO can simultaneously clear energy and reactive power market. Using the proposed method will result in decreasing the ISO payments to the participants. In other words, the value of objective function in the coupled market is lower than that of decoupled market. In addition, the results show that in both coupled and decoupled market, the ISO payment is greater in the case of the payment without PEVs in the market. This indicates the importance of the presence of PEVs in the market. 
Table 4: Optimal solution of decoupled and coupled active and reactive market

\begin{tabular}{|c|c|c|c|c|c|c|c|c|c|c|c|c|}
\hline \multirow[b]{2}{*}{ Case } & \multirow[b]{2}{*}{$\begin{array}{l}\text { Node } \\
\text { No. }\end{array}$} & \multirow[b]{2}{*}{$\begin{array}{l}\text { PEV } \\
\text { No. }\end{array}$} & \multicolumn{5}{|c|}{ Coupled Market } & \multicolumn{5}{|c|}{ Decoupled Market } \\
\hline & & & $P_{\text {generated }}(\mathrm{kW})$ & $\begin{array}{l}\text { Qgenerated } \\
(\mathrm{kVAr})\end{array}$ & $\begin{array}{l}\text { Energy } \\
\text { Cost }(\$)\end{array}$ & $\begin{array}{l}\text { TPF } \\
(\$)\end{array}$ & $\begin{array}{l}\text { LOC } \\
(\$)\end{array}$ & $\begin{array}{l}P_{\text {generated }}(\mathrm{kVA} \\
\mathrm{r})\end{array}$ & $\begin{array}{l}\mathrm{Q}_{\text {generated }} \\
\text { (kVAr) }\end{array}$ & $\begin{array}{l}\text { Energy } \\
\text { Cost } \\
(\$)\end{array}$ & $\begin{array}{l}\text { TPF } \\
(\$)\end{array}$ & $\begin{array}{l}\mathrm{LOC} \\
(\$)\end{array}$ \\
\hline \multirow{20}{*}{$\begin{array}{c}\text { With } \\
\text { Participation } \\
\text { of PEVs }\end{array}$} & 3 & 1 & 2.46 & 0.78 & 14.15 & 0.25 & 1.5 & 3.38 & 4.45 & 19.44 & 2.32 & 0 \\
\hline & 14 & 2 & 1.4 & 0.5 & 8.05 & 0.11 & 1.62 & 1.71 & 4.7 & 9.83 & 4.13 & 1.68 \\
\hline & 17 & 3 & 2.19 & 3.39 & 12.59 & 4.72 & 0.38 & 4.57 & 2.1 & 26.28 & 0.16 & 0 \\
\hline & 23 & 4 & 4.56 & 2.05 & 26.22 & 1.73 & 0 & 2.45 & 4.36 & 14.09 & 11.17 & 4.64 \\
\hline & 33 & 5 & 2.02 & 1.88 & 11.62 & 1.45 & 5.99 & 4.99 & 0.36 & 28.69 & 18.49 & 9.6 \\
\hline & 36 & 6 & 1.04 & 4.89 & 6 & 9.81 & 0 & 0 & 3.95 & 0 & 1.33 & 0 \\
\hline & 52 & 7 & 1.01 & 1.19 & 5.81 & 0.58 & 3.85 & 3.54 & 3.43 & 20.36 & 3.14 & 0 \\
\hline & 64 & 8 & 0.3 & 4.31 & 1.72 & 7.62 & 9.04 & 2.85 & 4.11 & 16.39 & 7.28 & 3.79 \\
\hline & 77 & 9 & 0.67 & 4.14 & 3.85 & 7.03 & 1.17 & 4.05 & 2.99 & 23.29 & 1.89 & 0 \\
\hline & 68 & 10 & 0.08 & 2.33 & 0.46 & 2.23 & 5.52 & 4.07 & 1.93 & 23.4 & 2.52 & 0 \\
\hline & 89 & 11 & 1.52 & 1.22 & 8.74 & 0.61 & 0 & 0 & 2.26 & 0 & 0.16 & 0 \\
\hline & 92 & 12 & 0.6 & 2.04 & 3.45 & 1.71 & 4.53 & 2.28 & 4.45 & 13.11 & 21.16 & 10.27 \\
\hline & 104 & 13 & 3.31 & 3.75 & 19.02 & 5.77 & 0.03 & 4 & 2.91 & 23 & 0.82 & 0 \\
\hline & 106 & 14 & 0.38 & 0.22 & 2.19 & 0.11 & 0 & 0 & 4.54 & 0 & 5.24 & 0 \\
\hline & 116 & 15 & 2.35 & 1.84 & 13.51 & 1.39 & 1.06 & 3.04 & 3.44 & 17.48 & 0.16 & 0 \\
\hline & 130 & 16 & 2.63 & 2.72 & 15.12 & 3.04 & 0.7 & 3.36 & 3.7 & 19.32 & 24.2 & 10.69 \\
\hline & 131 & 17 & 0.61 & 3.35 & 3.51 & 4.6 & 0 & 0 & 2.83 & 0 & 0.37 & 0 \\
\hline & Grid Gen. & - & 406.39 & 187.58 & 2336.76 & 145.72 & 0 & 406.71 & 160.27 & 2338.58 & 491.42 & 326.81 \\
\hline & $\Sigma$ & & 433.52 & 228.18 & 2492.77 & 198.48 & 35.39 & 451.19 & 216.78 & 2593.26 & 595.96 & 412.92 \\
\hline & \multicolumn{2}{|c|}{$\begin{array}{c}\sum(\text { Energy Cost }+ \text { LOC } \\
\text { Cost }+ \text { TPF Cost })\end{array}$} & \multicolumn{5}{|c|}{$2492.77+35.39+198.48=2726.64$ cent of dollar } & \multicolumn{2}{|c|}{$\begin{array}{c}\text { ( Energy Cost + TPF } \\
\text { Cost }) \\
\end{array}$} & \multicolumn{3}{|c|}{$\begin{array}{c}2593.26+412.92=\mathbf{3 0 0 6 . 1 8} \\
\text { cent of dollar }\end{array}$} \\
\hline \multirow{2}{*}{$\begin{array}{l}\text { Without } \\
\text { Participation } \\
\text { of PEVs }\end{array}$} & Grid Gen. & - & 467.99 & 218.41 & 2690.94 & 238.69 & 36.41 & 451.19 & 217.03 & 2439 & 1503.39 & 1269.04 \\
\hline & \multicolumn{2}{|c|}{$\begin{array}{c}\sum(\text { Energy Cost }+\mathrm{LOC} \\
\text { Cost }+ \text { TPF Cost })\end{array}$} & \multicolumn{5}{|c|}{$2690.94+36.41+238.69=\mathbf{2 9 6 6 . 0 4}$ cents of dollar } & \multicolumn{2}{|c|}{$\begin{array}{c}\sum \text { ( Energy Cost }+ \text { TPF } \\
\text { Cost })\end{array}$} & \multicolumn{3}{|c|}{$\begin{array}{c}2439+1269.04=3708.04 \\
\text { cents of dollar }\end{array}$} \\
\hline
\end{tabular}

\section{V.REFERENCES}

[1] M. Gitizadeh and M. Kalantar. A novel approach for optimum allocation of FACTS devices using multi-objective function. Energy conversion and Management 2009; 50:682-690.

[2] A. Lashkar Ara, A. Kazemi, and S. Niaki. Multiobjective optimal location of FACTS shunt-series controllers for power system operation planning. Power Delivery, IEEE Transactions on 2012; 27:481-490.

[3] J. Zhong and K. Bhattacharya. Toward a competitive market for reactive power. Power Systems, IEEE Transactions on 2002; 17:1206-1215.

[4] H. F. Farahani, H. Shayanfar, and M. Ghazizadeh. Incorporation of plug in hybrid electric vehicle in the reactive power market. Journal of Renewable and Sustainable Energy 2012; 4:053123.

[5] H. F. Farahani, H. Shayanfar, and M. Ghazizadeh. Multi-objective clearing of reactive power market including plug-in hybrid electric vehicle. Electric Power Components and Systems 2013; 41:197-220.

[6] H. F. Farahani, H. Shayanfar, and M. Ghazizadeh. Modeling of stochastic behavior of plug-in hybrid electric vehicle in a reactive power market. Electrical Engineering 2014; 96:1-13.

[7] A. Rabiee, H. Shayanfar, and N. Amjady. Coupled energy and reactive power market clearing considering power system security. Energy conversion and Management 2009; 50:907-915.

[8] J. Y.Guo, G. Venkataramanan, B. Lesieutre, A. Smick, M. Mallette, and C. Getter, "Environmental and Economic Research and Development Program, Consumer Adoption and Impact Models for Pug-in Hybrid Electric Vehicles in Wisconsin," May 2010.

[9] M. C. Kisacikoglu, B. Ozpineci, and L. M. Tolbert. Examination of a PHEV bidirectional charger system for V2G reactive power compensation. In: Applied Power Electronics Conference and Exposition (APEC), 2010 Twenty-Fifth Annual IEEE; 2010; Conference, Location. pp. $458-465$

[10]C. Quinn, D. Zimmerle, and T. H. Bradley. The effect of communication architecture on the availability, reliability, and economics of plug-in hybrid electric vehicle-to-grid ancillary services. Journal of Power Sources 2010; 195:1500-1509.

[11]J. Wang, C. Liu, D. Ton, Y. Zhou, J. Kim, and A. Vyas. Impact of plug-in hybrid electric vehicles on power systems with demand response and wind power. Energy Policy 2011; 39:4016-4021.

[12]F. Islam, H. Pota, and A. Nasiruzzaman. PHEV's park as a virtual active filter for HVDC networks. In: Environment and Electrical Engineering (EEEIC), 2012 11th International Conference on; 2012; Conference, Location. pp. 885-890.

[13]F. Islam and H. Pota. PHEVs Park as Virtual UPFC. TELKOMNIKA Indonesian Journal of Electrical Engineering 2012; 10:2285-2294.

[14]N. S. Rau. Optimal dispatch of a system based on offers and bids-a mixed integer LP formulation. IEEE Trans Power Syst 1999; 14:274-279.

[15]X. Ma, D. Sun, and K. Cheung. Energy and reserve dispatch in a multizone electricity market. IEEE Trans Power Syst 1999; 14:913-919.

[16] T. Wu, M. Rothleder, Z. Alaywan, and A. D. Papalexopoulos. Pricing energy and ancillary services in integrated market systems by an optimal power flow. IEEE Trans Power Syst 2004; 19:339-347.

[17]A. Rabiee, H. Shayanfar, and N. Amjady. Multiobjective clearing of reactive power market in deregulated power systems. Applied energy 2009; 86:1555-1564.

[18]N. Amjady, A. Rabiee, and H. Shayanfar. Pay-as-bid based reactive power market. Energy Conversion and Management 2010; 51:376-381.

[19]A. Rabiee, H. A. Shayanfar, and N. Amjady. Reactive power pricing [The Business Scene]. Power and Energy Magazine, IEEE 2009; 7:18-32.

[20]A. Brooks, D. R. E. Lu, C. Spirakis, and B. Weihl. Demand dispatch: Using real-time control of demand to help balance generation and load. IEEE Power Energy Mag May/Jun. 2010.; 8:20-29.

[21]D.-Z. Du, P. M. Pardalos, and W. Wu, Mathematical theory of optimization vol. 56: Springer Science \& Business Media, 2013.

[22]R. Horst, P. M. Pardalos, and N. Van Thoai, Introduction to global optimization: Springer Science \& Business Media, 2000.

[23]P. Richardson, D. Flynn, and A. Keane. Optimal charging of electric vehicles in low-voltage distribution systems. Power Systems, IEEE 
Transactions on $2012 ; 27: 268-279$.

[24]W. Su, H. Rahimi-Eichi, W. Zeng, and M. Y. Chow. A Survey on the Electrification of Transportation in a Smart Grid Environment. IEEE Trans. on Industrial Informatics 2012; 8:1-10.

[25]Electric Vehicle Charging Infrastructure Deployment Guidelines for the Oregon I-5 Metro Areas of Portland, Salem, Corvallis and Eugene.
Electric Transportation Engineering Corporation, [Online] http://www.oregon.gov/ODOT/HWY/OIPP/docs/EVDeployGuide lines3-1.pdf 2010. 